\title{
Sit down and read on: Working memory and long-term memory in particle-verb processing
}

\author{
Vitória Piai $^{\mathrm{a}, \mathrm{b}, *}$, Lars Meyer ${ }^{\mathrm{c}}$, Robert Schreuder ${ }^{\mathrm{a}, 1}$, Marcel C.M. Bastiaansen ${ }^{\mathrm{d}, \mathrm{e}}$ \\ ${ }^{a}$ Radboud University Nijmegen, Donders Institute for Brain, Cognition and Behaviour, Montessorilaan 3, 6525 HR, Nijmegen, The Netherlands \\ b International Max Planck Research School for Language Sciences, Wundtlaan 1, 6525 XD, Nijmegen, The Netherlands \\ ${ }^{\mathrm{c}}$ Max Planck Institute for Human Cognitive and Brain Sciences, Stephanstraße 1A, 04103 Leipzig, Germany \\ ${ }^{\mathrm{d}}$ Max Planck Institute for Psycholinguistics, Wundtlaan 1, 6525 XD, Nijmegen, The Netherlands \\ ${ }^{\mathrm{e}}$ NHTV Breda University of Applied Sciences, Academy for Leisure, Breda. The Netherlands
}

\section{A R T I C L E I N F O}

\section{Article history:}

Accepted 30 September 2013

Available online 1 November 2013

We dedicate this article to Robert Schreuder, who unfortunately did not live to see its realisation.

\section{Keywords:}

Anterior negativity

Lexical access

Long-term memory

N400

Particle verb

Syntactic dependency

Working memory

\begin{abstract}
A B S T R A C T
Particle verbs (e.g., look up) are lexical items for which particle and verb share a single lexical entry. Using event-related brain potentials, we examined working memory and long-term memory involvement in particle-verb processing. Dutch participants read sentences with head verbs that allow zero, two, or more than five particles to occur downstream. Additionally, sentences were presented for which the encountered particle was semantically plausible, semantically implausible, or forming a non-existing particle verb. An anterior negativity was observed at the verbs that potentially allow for a particle downstream relative to verbs that do not, possibly indexing storage of the verb until the dependency with its particle can be closed. Moreover, a graded N400 was found at the particle (smallest amplitude for plausible particles and largest for particles forming non-existing particle verbs), suggesting that lexical access to a shared lexical entry occurred at two separate time points.
\end{abstract}

(c) 2013 Elsevier Inc. All rights reserved.

\section{Introduction}

Whenever we encounter a word in a sentence, we retrieve its meaning and morphosyntactic information from long-term memory (i.e., the mental lexicon; Ullman, 2001). While most lexical entries correspond to a single word each in the syntactic structure, verbal compounds (e.g., look up), which are stored as single lexical entries (Cappelle, Shtyrov, \& Pulvermüller, 2010; Jackendoff, 2002), are expressed by multiple words in the syntactic structure (McIntyre, 2007). We follow the literature by using the term "particle verbs" to refer to these constructions.

In Dutch, particle verbs consist of a head verb and a particle, which can be a preposition or an adverb. In a sentence, other lexical units can separate a verb and its particle (Booij, 1990). An example is given in (1), with the head verb and the particle indicated in subscript:

$\begin{array}{lllllllll}\text { De } & \text { bank } & \text { spiegelt }_{(\mathrm{V})} & \text { haar } & \text { nieuwste } & \text { klanten } & \text { hoge } & \text { winsten } & \text { voor } \\ & \text { The } & \text { bank } & \text { mirrors }_{(\mathrm{V})} & \text { her } & \text { newest } & \text { customers } & \text { high } & \text { profit } \\ & \text { before } & \end{array}$

\footnotetext{
* Corresponding author. Address: Radboud University Nijmegen, Donders Institute for Brain, Cognition and Behaviour, Centre for Cognition, Spinoza Building B.01.05, Montessorilaan 3, 6525 HR Nijmegen, The Netherlands. Fax: +31 24 3612635.

E-mail addresses: v.piai@donders.ru.nl (V. Piai), Imeyer@cbs.mpg.de (L. Meyer), bastiaansen4.m@nhtv.nl (M.C.M. Bastiaansen).

Deceased.
}

In (1), the verb $(\mathrm{V})$ and its particle $(\mathrm{P})$ form a non-adjacent dependency: Particle processing requires prior verb processing, such that the verb's syntactic and semantic properties can be assigned to the particle (Hawkins, 1999, 2004). Conversely, the verb of a sentence involving a particle verb can only be interpreted once its particle has been encountered: In (1), the idiomatic meaning 'promises' can only be accessed after recognising the particle voor 
six words downstream from its verb. In (1), particle-verb recognition involves both a primary and a secondary lexical access. In addition to this lexical dependency, verb-particle dependencies may have a syntactic dimension (Hoekstra, 1988; Hoekstra, Lansu, \& Westerduin, 1987), involving the upstream verb and its stranded particle (Booij, 2002). In addition to their dual nature, particle-verb dependencies are different from purely syntactic dependencies (e.g., relative pronouns, topicalisation, wh-movement) in that most particle verbs can also appear without a particle, resulting in an uncertain dependency.

While their dual nature and uncertainty differentiate verbparticle dependencies from other dependencies, verb-particle dependencies share their working-memory reliance with other types of syntactic dependencies. As exemplified in (1), any number of words can intervene between the verb and the particle; thus, the first dependent (i.e., the verb) must be held in working memory until the second dependent (i.e., the particle) is encountered. While previous EEG research has associated frontal negative ERP components with the working-memory storage of syntactically dependent elements (relative pronouns: King \& Kutas, 1995; Ueno \& Garnsey, 2008; topicalisation: Felser, Clahsen, \& Münte, 2003; wh-movement constructions: Fiebach, Schlesewsky, \& Friederici, 2002; Kluender \& Kutas, 1993; Phillips, Kazanina, \& Abada, 2005), only few studies have experimentally approached the comprehension of particle verbs in sentence context (Frazier, Flores d'Arcais, \& Coolen, 1993; Smolka, Komlósi, \& Rösler, 2009; Zwitserlood, Bolwiender, \& Drews, 2004; for production, see Konopka \& Bock, 2008) and even fewer have done so using techniques with high temporal resolution, such as ERPs (Cappelle et al., 2010; Isel, Alter, \& Friederici, 2005). As a result, existing psycholinguistic models of particle-verb processing are incomplete (e.g., Hillert \& Ackerman, 2002; Schreuder, 1990).

The present study aimed at examining the involvement of working memory (dependency formation) and long-term memory (mental-lexicon access) in the processing of particle-verb dependencies. We carried out an experiment with Dutch participants who read sentences while their electroencephalogram (EEG) was recorded. Two research questions were addressed, described separately below, with independent sets of sentences used to test effects respectively at the upstream verb and sentence object, and at the downstream particle.

\subsection{Syntactic dependencies and working memory}

The first research question addressed whether the language system exhibits early sensitivity to the possibility that an upstream verb is followed by a downstream particle. As mentioned above, the verb and the particle syntactically depend on each other, which means that the first dependent (i.e., the verb) must be held in working memory until the second dependent (i.e., the particle) is encountered, increasing the working-memory demand. However, these dependencies are often uncertain, that is, the verb may occur without a downstream particle. So in the case of uncertain dependencies, two scenarios are possible: First, the upstream verb might be processed like any other verb, and the presence of a particle verb would only be diagnosed upon encountering the particle. Since many particle verbs can also occur without particles, it might be uneconomical to pre-allocate working-memory resources early in the sentence for the potential occurrence of a downstream particle (Gibson, 1998; Isel et al., 2005). Alternatively, the presence of a particle verb might be postulated already at the verb, resulting in the pre-allocation of working-memory resources for verbs that are potentially followed by their particle.

To investigate this question, ERPs to sentences with verbs that occur both with and without a particle in Dutch were compared with the ERPs to sentences with verbs that only occur without a particle. Left anterior negativities (LANs) have previously been associated with the maintenance of lexical items active in working memory for later integration (for review, see Kutas, van Petten, \& Kluender, 2006). If the presence of a particle verb is signalled already at the verb, a LAN is a likely ERP component to reflect the increased working-memory demands associated with processing the verb.

Furthermore, we investigated whether the number of possible particles associated with a verb influences processing already at the upstream verb. That is, if the possibility of a particle occurring later in the sentence is already taken into consideration at the verb, it could be the case that verbs that only allow for a small number of different particles would require relatively less processing effort compared to verbs that allow for a large number of different particles, due to reduced competition in lexical access (Isel et al., 2005; Magnuson, Dixon, Tanenhaus, \& Aslin, 2007; Revill, Aslin, Tanenhaus, \& Bavelier, 2008). In this case, the amplitude of the LAN should increase parametrically as a function of the number of possible particle verbs that can be formed with the main verb. Alternatively, if the most important information for the system at the verb is whether or not a particle is likely to follow downstream, then the system may not be sensitive to the number of possible particles, but rather to the mere possibility of a particle completion. In this case, the amplitude of the LAN should be similar regardless of the number of particles that a verb can take. To investigate this issue, we manipulated our experimental materials such that ERPs could be compared following the encounter of verbs licensing only two or three particles, at least five particles, or no particle at all.

In short, three sets of verbs were used, forming the Large set, Small set, and No particle conditions. The sentences had a fixed syntactic structure: subject, verb, object (and particle in the case of the particle-verb conditions). For example, the verb spannen 'to tense' can be combined with at least seven particles in Dutch, whereas kleuren 'to colour' can only be combined with two particles, and negeren 'to ignore' does not allow for any particle. The sentences were formed such that these three types of verbs and the downstream objects in the sentences could be contrasted with each other. Table 1 (upper three conditions) gives an example of the experimental sentences for this research question. More examples can be found in the Supplement.

\subsection{Lexical access and long-term memory}

Our second research question addressed the process of lexical access in long-term memory in particle-verb processing: Whereas a particle verb has a single entry in the mental lexicon (cf. Cappelle et al., 2010), the time frame for single word recognition (150200 ms; Hauk, Davis, Ford, Pulvermüller, \& Marslen-Wilson, 2006; Pulvermüller \& et al., 2001), is too small to recognise an entire particle verb when the particle occurs downstream in the sentence. Hence, the recognition of a particle verb's lexical entry may require both a first lexical access on head-verb encounter and a second lexical access on particle encounter.

To examine lexical access in particle-verb processing, we constructed Dutch sentences involving particle verbs while varying the particle in three different ways: For a verb that allows for a particle, the downstream particle could be (a) a particle forming an existing, semantically interpretable particle verb, fitting the sentence context (Well-formed condition); (b) a particle that, combined with the head verb, would form an existing particle verb whose meaning does not fit the sentence context (Semantic violation condition); or (c) a particle that, combined with the verb, would form a non-existing particle verb, which has no meaning and therefore also does not fit the sentence context (Morpholexical violation condition). Thus, the sentences across the three 
Table 1

Stimulus examples.

\begin{tabular}{|c|c|c|c|c|c|c|c|c|c|c|c|}
\hline \multirow{2}{*}{$\frac{\text { Condition }}{\text { Large set }}$} & \multicolumn{11}{|c|}{ Stimulus sentence } \\
\hline & $\begin{array}{l}\text { Ik } \\
\text { I }\end{array}$ & $\begin{array}{l}\operatorname{deel}_{(\mathrm{V})} \\
\operatorname{divide}_{(\mathrm{V})}\end{array}$ & $\begin{array}{l}\text { mijn } \\
\text { my }\end{array}$ & $\begin{array}{l}\text { week } \\
\text { week }\end{array}$ & $\begin{array}{l}\operatorname{in}_{(P)} \\
\operatorname{in}_{(P)}\end{array}$ & $\begin{array}{l}\text { zonder } \\
\text { without }\end{array}$ & $\begin{array}{l}\text { mijn } \\
\text { my }\end{array}$ & $\begin{array}{l}\text { agenda } \\
\text { calendar }\end{array}$ & & & \\
\hline Small set & $\begin{array}{l}\text { 'I sol } \\
\text { Ik } \\
\text { I }\end{array}$ & $\begin{array}{l}\text { my week w } \\
\text { verdien }_{(\mathrm{V})} \\
\operatorname{earn}_{(\mathrm{V})}\end{array}$ & $\begin{array}{l}\text { ut looking } \\
\text { wat } \\
\text { what }\end{array}$ & $\begin{array}{l}\text { yy calend } \\
\text { geld } \\
\text { money }\end{array}$ & $\begin{array}{l}\operatorname{bij}_{(\mathrm{P})} \\
\mathrm{by}_{(\mathrm{P})}\end{array}$ & $\begin{array}{l}\text { met } \\
\text { with }\end{array}$ & $\begin{array}{l}\text { mijn } \\
\text { my }\end{array}$ & $\begin{array}{l}\text { bijbaantje } \\
\text { side }\end{array}$ & job & & \\
\hline Simplex set & $\begin{array}{l}\text { 'I ea } \\
\text { Bo } \\
\text { Bo } \\
\text { 'Bo i }\end{array}$ & $\begin{array}{l}\text { me extra mo } \\
\text { aarzelt }_{(\mathrm{V})} \\
\text { hesitates } \\
\text { sitant in leav }\end{array}$ & $\begin{array}{l}\text { with my s } \\
\text { haar } \\
\text { her } \\
\text { er city' }\end{array}$ & $\begin{array}{l}\text { ob' } \\
\text { stad } \\
\text { city }\end{array}$ & $\begin{array}{l}\text { te } \\
\text { to }\end{array}$ & $\begin{array}{l}\text { verlaten } \\
\text { leave }\end{array}$ & & & & & \\
\hline Control & $\begin{array}{l}\text { De } \\
\text { The } \\
\text { 'The }\end{array}$ & $\begin{array}{l}\text { arts } \\
\text { doctor } \\
\text { or x-rays the }\end{array}$ & $\begin{array}{l}\text { licht }_{(\mathrm{V})} \\
\text { lights }(\mathrm{V}) \text {. } \\
\text { ent's lung }\end{array}$ & $\begin{array}{l}\text { de } \\
\text { the }\end{array}$ & $\begin{array}{l}\text { longen } \\
\text { lungs }\end{array}$ & $\begin{array}{l}\text { van } \\
\text { of }\end{array}$ & $\begin{array}{l}\text { de } \\
\text { the }\end{array}$ & $\begin{array}{l}\text { patiënt } \\
\text { patient }\end{array}$ & $\begin{array}{l}\operatorname{door}_{(\mathrm{P})} \\
\text { through }_{(\mathrm{P})}\end{array}$ & $\begin{array}{l}\text { met } \\
\text { with }\end{array}$ & $\begin{array}{l}\text { een... } \\
\text { a.... }\end{array}$ \\
\hline Semantic & $\begin{array}{l}\text { De } \\
\text { The } \\
\text { ?'Th }\end{array}$ & $\begin{array}{l}\text { arts } \\
\text { doctor } \\
\text { ctor clarifies }\end{array}$ & $\begin{array}{l}\text { licht }_{(\mathrm{V})} \\
\text { lights }_{(\mathrm{V})} \\
\text { patient's l }\end{array}$ & $\begin{array}{l}\text { de } \\
\text { the }\end{array}$ & $\begin{array}{l}\text { longen } \\
\text { lungs }\end{array}$ & $\begin{array}{l}\text { van } \\
\text { of }\end{array}$ & $\begin{array}{l}\text { de } \\
\text { the }\end{array}$ & $\begin{array}{l}\text { patiënt } \\
\text { patient }\end{array}$ & $\begin{array}{l}\operatorname{toe}_{(\mathrm{P})} \\
\text { to }_{(\mathrm{P})}\end{array}$ & $\begin{array}{l}\text { met } \\
\text { with }\end{array}$ & $\begin{array}{l}\text { een... } \\
\text { a... }\end{array}$ \\
\hline Morpho-Lexical & $\begin{array}{l}\text { De } \\
\text { The } \\
\text { ? }\end{array}$ & $\begin{array}{l}\text { arts } \\
\text { doctor }\end{array}$ & $\begin{array}{l}\text { licht }_{(\mathrm{V})} \\
\text { lights }_{(\mathrm{V})}\end{array}$ & $\begin{array}{l}\text { de } \\
\text { the }\end{array}$ & $\begin{array}{l}\text { longen } \\
\text { lungs }\end{array}$ & $\begin{array}{l}\text { van } \\
\text { of }\end{array}$ & $\begin{array}{l}\text { de } \\
\text { the }\end{array}$ & $\begin{array}{l}\text { patiënt } \\
\text { patient }\end{array}$ & $\begin{array}{l}\operatorname{af}_{(\mathrm{P})} \\
\operatorname{off}_{(\mathrm{P})}\end{array}$ & $\begin{array}{l}\text { met } \\
\text { with }\end{array}$ & $\begin{array}{l}\text { een... } \\
\text { a.... }\end{array}$ \\
\hline
\end{tabular}

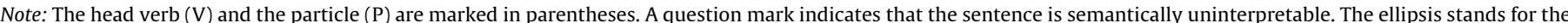
remaining of the sentence, "new method".

conditions were identical except for the particle. This particle gradually varied the sentences from semantically well-formed, towards semantically ill-formed with an existing particle verb, towards semantically ill-formed with a non-existing particle verb. So, for example, a sentence was constructed containing the verb bellen 'to call', which exists in combination with the particle af 'off' ('to call off') and with the particle terug 'back' ('to call back'), but not with the particle toe 'to'. The sentences were identical except for the particle being presented: Wij bellen de afspraak van vanmiddag af/terug/toe 'We call the appointment of this afternoon off/back/to', yielding a well-formed sentence ('we call off the appointment'), a semantic violation ('we call back the appointment'), or a morpholexical violation because the formed particle verb does not exist. Table 1 (lower three conditions) gives an example of the experimental sentences for this research question. More examples can be found in the Supplement.

Given that the sentences across conditions only differed in the particle, ERPs to the particle were analysed. Since we hypothesised that encountering a particle triggers a second(ary) lexical access, we expected increased ERP responses relative to those conditions involving semantically well-formed sentences and existing particle verbs. Specifically, we expected an increased N400 (Kutas \& Hillyard, 1980) amplitude for the condition with a non-existing particle verb relative to the condition with an existing particle verb, even though both conditions are semantically ill-formed: The amplitude of the N400 component has been found (amongst others) to reflect the ease of lexical access based on the preceding (sentence) context (Kutas, 1993; Kutas \& Federmeier, 2011; Kutas et al., 2006; Lau, Phillips, \& Poeppel, 2008). A note of caution is in place with respect to the interpretation of the N400 effect in terms of lexical access. N400 modulations have also been observed as a function of various phenomena that are not connected to lexical access (e.g. Choudhary, Schlesewsky, Roehm, \& BornkesselSchlesewsky, 2009; Haupt, Schlesewsky, Roehm, Friederici, \& Bornkessel-Schlesewsky, 2008; Janssen, Wiese, \& Schlesewsky, 2006). However, the large majority of N400 studies suggest that, in most cases, N400 effects are indicative of (1) ease of lexical access owing to the word's preceding context and (2) integration of the word with the preceding context (see for reviews, Kutas \& Federmeier, 2011; Lau et al., 2008). Therefore, for the context of our study, we relate N400 effects to lexical access on the basis of a plausibility argument.

\section{Methods}

\subsection{Participants}

Thirty students participated (9 males, mean age $=22$ ). They were paid $€ 12$ for their participation. All participants gave written informed consent and the experiment was conducted according to the declaration of Helsinki (World Medical Association, 1995). All participants were right-handed, native speakers of Dutch with normal or corrected-to-normal vision. They had no history of neurological deficits nor were they under medication or drugs.

\subsection{Materials}

\subsubsection{Syntactic dependencies and working memory}

Table 1 (upper three conditions) gives an example of the experimental sentences for the first research question. Three sets of verbs were created using the Dutch Celex database (Baayen, Piepenbrock, \& van Rijn, 1995), with 31 verbs in each set. Verbs which allow for at least five particles were assigned to the Large set; verbs which appear in combination with two or three particles were assigned to the Small set; verbs which do not appear in combination with any particle at all were assigned to the No particle condition. All verbs used also occur without particles in Dutch. Ninety-three sentences were created (31 for each set using each verb only once) with a fixed syntactic structure: subject - verb object - (particle) - remainder. For example, the verbs spannen 'to tense' (seven particles in Dutch), kleuren 'to colour' (two particles), and negeren 'to ignore' (no particle) were used to form the following sentences: Joost spant zijn spieren aan tijdens de training 'Joost tenses up his muscles during the training', Maartje kleurt de plaatjes in met waskrijt en stiften 'Maartje colours the pictures with crayon and pencils', and I $k$ negeer de menigte om me heen 'I ignore the crowd around me' (verb and particle are indicated in bold).

Table 2 presents the characteristics of the particle verb sets from Celex. The two particle sets differed significantly from each other in the number of possible particles per head verb (unpaired $t(60)=10.4, p<.001$ ). Lemma frequency, verb length (in characters), and neighbourhood density were matched across conditions. An analysis of variance (ANOVA) revealed no systematic differences among the conditions for verb frequency, $F(2,90)<1$, $p=.975$; nor length, $F(2,90)=1.3, p=.274$; nor neighbourhood 
Table 2

Mean number of particles per head verb, and standard deviations, for the Large and Small Sets as entered into the Celex database (left) and as generated by participants in the pre-test (right).

\begin{tabular}{llllll}
\hline \multirow{2}{*}{ Condition } & \multicolumn{2}{l}{ Celex database } & & \multicolumn{2}{l}{ Particle verb generation pre-test } \\
\cline { 2 - 3 } \cline { 5 - 6 } & Mean & sd & & Mean & sd \\
\hline Large set & 8.5 & 3.2 & & 3.1 & 0.7 \\
Small set & 2.5 & 0.5 & & 1.7 & 0.4 \\
\hline
\end{tabular}

density, $F(2,90)<1, p=.639$. The lemma frequency, length of the object (in characters), and neighbourhood density were also matched across the three conditions, with no differences across conditions for frequency, $F(2,90)<1, p=.945$; nor length, $(F(2,90)<1, \quad p=.981$; nor neighbourhood density, $F(2,90)<1$, $p=.703$. Moreover, all verbs were transitive verbs (except for one ditransitive verb in the No particle condition) and morphologically simple (except for two verbs in the No particle condition, which had the prefix ver-, verwachten 'to expect' and verdienen 'to earn'). Objects were either morphologically simple, compounds, or contained suffixes (e.g., plural morpheme and diminutive morpheme). Importantly, however, the morphological complexity of the objects did not differ systematically across conditions (Morphologically simple objects: Large $=19$, Small $=18$, No particle $=19$; compounds: Large $=3$, Small $=5$, No particle $=4$; objects with suffixes: Large $=9$, Small $=8$, No particle $=8$ ).

2.2.1.1. Pre-tests. The stimulus materials were subjected to two pre-tests. First, we wanted to establish whether the two particleverb sets constructed based on the Celex database were equally acceptable to Dutch speakers. To this end, a particle-verb-generation task was performed by 16 native Dutch speakers. They were provided with each verb from the two particle-verb sets and instructed to generate as many particle verbs as they could. We counted the number of particle verbs generated by each participant for each verb, shown in Table 2 for the group average. Participants generated significantly more particle verbs for the Large Set compared to the Small Set (paired $t(30)=10.8, p<.001$ ). The average scores calculated for the verb generation task were highly correlated with the number of possible particle verbs for each verb in the Celex database $(r=.768, p<.001)$.

The second pre-test ensured that the contextual constraints were identical across the Large and Small Sets, to avoid potential context effects on the ERPs (Kutas \& Federmeier, 2011). In the materials, the subject of the sentences was always semantically neutral with relation to the verb, thus not biasing the context towards any expected meaning. We also controlled that all possible readings of each verb (including the variant without particle) were plausible on encountering the upstream verb. Contextual control was pre-tested with two sentence completion tasks. A group of participants $(N=16)$ saw the sentence materials up until and including the main verb and another group $(N=22)$ up until and including the object preceding the particle. The mean particle cloze probability (i.e. completions with the same particle as the one chosen for the materials; Bloom \& Fischler, 1980; Taylor, 1953) was $11.3 \%(s d=11.5 \%)$ at the main verb and $82.9 \%(s d=15.3 \%)$ at the object. At both positions, the cloze probabilities between the Small and Large sets did not differ (verb: unpaired $t(60)=1.1, p=.274$; object: unpaired $t(60)=1.1, p=.270$ ). A comparison of the cloze probabilities at the verb and the object differed (paired $t(61)=34.5, p<.001)$, indicating that participants did not predict the upcoming particle given only the subject of the sentence and the main verb, but that the context created by the object was constraining enough to converge towards one particle for each sentence.

\subsubsection{Lexical access and long-term memory}

Table 1 (lower three conditions) gives an example of the experimental sentences for the lexical-access question. The sentence materials consisted of 120 sentence triplets, all main clauses involving particle verbs. The triplets were created such that they differed only in the particle, for example, Wij bellen de afspraak van vanmiddag af/terug/toe 'We call the appointment of this afternoon off/back/to'. Thus, the same set of particles was used (e.g., af, toe, terug, uiteen) and therefore, there were no systematic differences in frequency $(F(2,117)<1, p=.773)$ nor length $(F(2,117)<1$, $p=.945)$ for the particles across conditions.

In the Well-formed condition, the particle encountered was a particle that yielded a fully grammatical, coherent sentence, e.g., afbellen: 'We call off the appointment'. In the Semantic violation condition, existing particle verbs were chosen whose meaning constituted a semantic anomaly in the sentence context, e.g., terugbellen: 'We call back the appointment'. In the Morpholexical violation condition, non-existing particle verbs were created by combining existing verbs (e.g., bellen) with mismatching existing particles (e.g., toe), also forming a semantically anomalous sentence, e.g., toebellen: 'We call to the appointment'. Only adverbial particles were used, because prepositional particles may be interpreted as prepositions, thus not yielding a violation at the point the particle is encountered. Adverbial particles, in turn, can only be interpreted as verb particles.

Sentences in all conditions were syntactically well-formed, but both violation conditions (Semantic and Morpholexical) were semantically anomalous, differing only in the existence of the particle verb. In all sentences, the verbs always preceded the particle, and verb and particle were either adjacent or separated by one to five words. The verbs were never the first element in the sentence and the particles never appeared in sentence-final position.

\subsection{Degree of semantic transparency}

Many particle verbs have an opaque meaning, that is, the meaning of the particle verb cannot be derived compositionally from the meanings of the verb and the particle (see for Dutch, Blom, 2005; Booij, 1990; Schreuder, 1990; for German, Smolka et al., 2009). Although we do not address this question in the present study, we quantified the degree of idiomaticity of the particle verbs used in our materials. For this test, an independent group of participants $(N=22)$ was presented with all grammatically and semantically correct particle-verb sentences of our materials (i.e., Large and Small set sentences and Well-formed sentences), one at a time on a computer screen, and asked to judge, on a 1-5 scale, how much the meaning of the particle verb in each sentence was related to the meaning of the associated head verb $(1=$ no relation at all, $5=$ highly related). All our particle verbs were relatively semantically transparent (mean rating Large set $=3.5$, mean rating Small set $=3.2$, mean rating Well-formed $=3.3$ ). The degree of transparency, as judged by participants, did not differ between the Large and Small sets, $t(30)=1.77, p=.086$.

\subsection{Experimental lists}

From the Lexical Access materials, 40 sentences of each condition were put into three lists, counterbalanced according to an orthogonal Latin-square design. These three lists also contained the 93 sentences from the Syntactic Dependencies materials. Additionally, 47 fillers were created without particle verbs to avoid strong particle-completion biases. Twenty-three fillers contained a semantic violation, such as He tortures his pencils. The other 24 fillers contained a syntactic violation, such as He is flirting in that girl. There were 260 sentences per list in total, presented in random 
order. Finally, the order of items in each list was randomised individually for each participant.

\subsection{Procedure}

Participants were tested individually in an electrically and acoustically shielded booth. They were instructed to read the sentences silently for comprehension and to blink only when three asterisks were shown. No additional task was imposed. The experimenter could monitor the participant via a camera and contact was possible via an intercom. Sentences were presented word by word (Tahoma font, size 30) in black on a white background in the centre of a computer screen (resolution: $1024 \times 768 \times 16$ ). The experiment started with a short practice of five trials with sentences that were not in the experiment. A trial began with three asterisks, which were presented for $3 \mathrm{~s}$, indicating that participants were allowed to blink. A fixation cross, which remained on screen for $1 \mathrm{~s}$, followed the asterisks indicating that the trial was about to start. A blank screen followed the fixation cross for $300 \mathrm{~ms}$ until the first word of the sentence appeared. Each word in the sentence was presented for $300 \mathrm{~ms}$ followed by a blank screen for $300 \mathrm{~ms}$. The materials were presented in 13 short blocks of 20 sentences each, with a break between each block. Participants decided how long the breaks lasted by pressing a button to proceed to the next block. Each block lasted about 3.5 min. The whole session, including preparation, lasted around $1 \mathrm{~h}$ and 20 min.

\subsection{EEG recording}

The EEG was recorded from 60 scalp electrodes mounted equidistantly in an elastic cap using the Acticap system, amplified with BrainAmp DC amplifiers ( $500 \mathrm{~Hz}$ sampling rate, $0.016-100 \mathrm{~Hz}$ band-pass filter). The EEG-cap configuration is shown in Fig. 1. The EEG was referenced on-line to the left mastoid, and rereferenced off-line to averaged mastoids. The horizontal electrooculogram (EOG) was recorded from two electrodes placed on the left and right temples. The vertical EOG was recorded from two electrodes positioned below and above the left eye. Electrode impedance was kept below $10 \mathrm{k} \Omega$.

\subsection{ERP analysis}

The EEG was band-pass filtered with a phase-shift-free Butterworth filter of 0.1 ( $48 \mathrm{~dB} /$ oct) to 30 ( $48 \mathrm{~dB} /$ oct, time constant $1.6 \mathrm{~s}) \mathrm{Hz}$. The data were then divided into epochs consisting of $150 \mathrm{~ms}$ pre-onset until $1 \mathrm{~s}$ following the onset of the critical words.

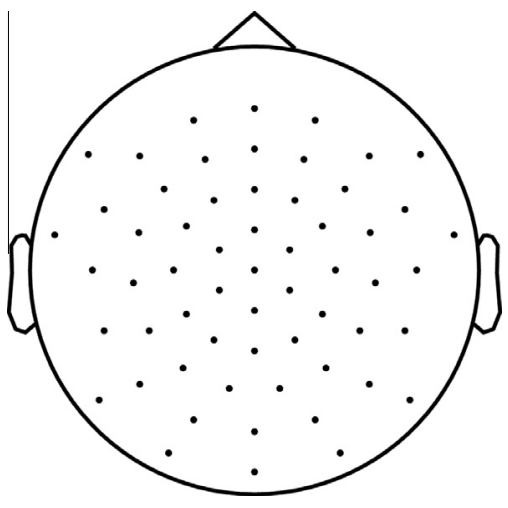

Fig. 1. Configuration of the EEG cap used in the experiment. Each dot corresponds to a channel.
For the first question (Syntactic Dependencies and Working Memory), we defined two critical words: the verb and the object. (The particle segment was also analysed but is not reported because differences between conditions in the baseline period rendered the results uninterpretable, see Supplement). For the second question (Lexical Access and Long-Term Memory), the critical word was the particle. Single waveforms were baseline-corrected using the average EEG activity in the interval between $150 \mathrm{~ms}$ pre-stimulus to the onset of each critical word. Epochs were visually inspected and those containing eye movements, electrode drifts, or muscular artefacts were rejected (6.3\% of the trials). For each critical word, average waveforms were computed for each participant across all trials per condition.

\subsection{Statistical analysis}

We used non-parametric cluster-based permutation tests for the statistical analysis (Maris \& Oostenveld, 2007). In essence, this statistical test is time- and channel-uninformed: The full timechannel space is blindly scanned for adjacent time points and channels that exhibit a similar difference across conditions. Thus, scalp topography is naturally incorporated into the statistical comparison. The false alarm rate of this test is controlled at the alpha level (in this study, 0.05) that is used for determining statistical significance (see also Groppe, Urbach, \& Kutas, 2011). We refer to Maris and Oostenveld (2007) for a detailed description of the approach. Here, we present the parameters that were specific to the conducted analyses. All available time points were included in the analysis, i.e., from $150 \mathrm{~ms}$ pre-stimulus to $1 \mathrm{~s}$ post-stimulus. All channel-time point pairs whose $t$-values were larger than \pm 2.05 (i.e., an alpha level of .05 with 29 degrees of freedom) were selected and clustered on the basis of temporal and spatial adjacency. Channels were set to have, on average, three neighbours. For temporal adjacency, the criterion was one sample point, i.e., $2 \mathrm{~ms}$. One thousand random permutations were used. A Monte-Carlo cluster p-value below .05 (two-tailed testing) was considered significant. For the first question (Syntactic Dependencies and Working Memory), the analyses were conducted by comparing the Large set, Small set, and No particle conditions pair-wise for each critical word separately. For the second question (Lexical Access and Long-Term Memory), the analyses were conducted by comparing the Well-formed, Semantic violation, and Morpholexical violation conditions in a pair-wise fashion.

\section{Results}

\subsection{Syntactic dependencies and working memory}

In the results presented below, we compared the ERPs to the verb and to the object across the three conditions (e.g., Large set:

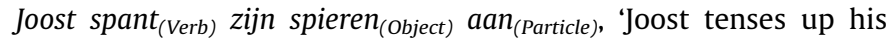
muscles'; Small set: Maartje kleurt $_{(\text {Verb) }}$ de plaatjes $_{(\text {object) }}$ in $_{(\text {Particle })}$, 'Maartje colours the pictures'; No particle: $I k$ negeer $_{(V e r b)}$ de menigte $_{(\text {object) }}$, 'I ignore the crowd').

\subsubsection{Verb}

Fig. 2 shows the ERPs to the verb for nine representative channels. The position of these nine channels is highlighted in the topographies on the right. An increased negativity was detected for the Large set relative to the No particle condition, $p=.043$, and for the Small set relative to the No particle condition, $p=.024$. This increased negativity was detected between 284 and $540 \mathrm{~ms}$ for the Large set relative to the No particle condition, and between 260 and $548 \mathrm{~ms}$ for the Small set relative to the No 

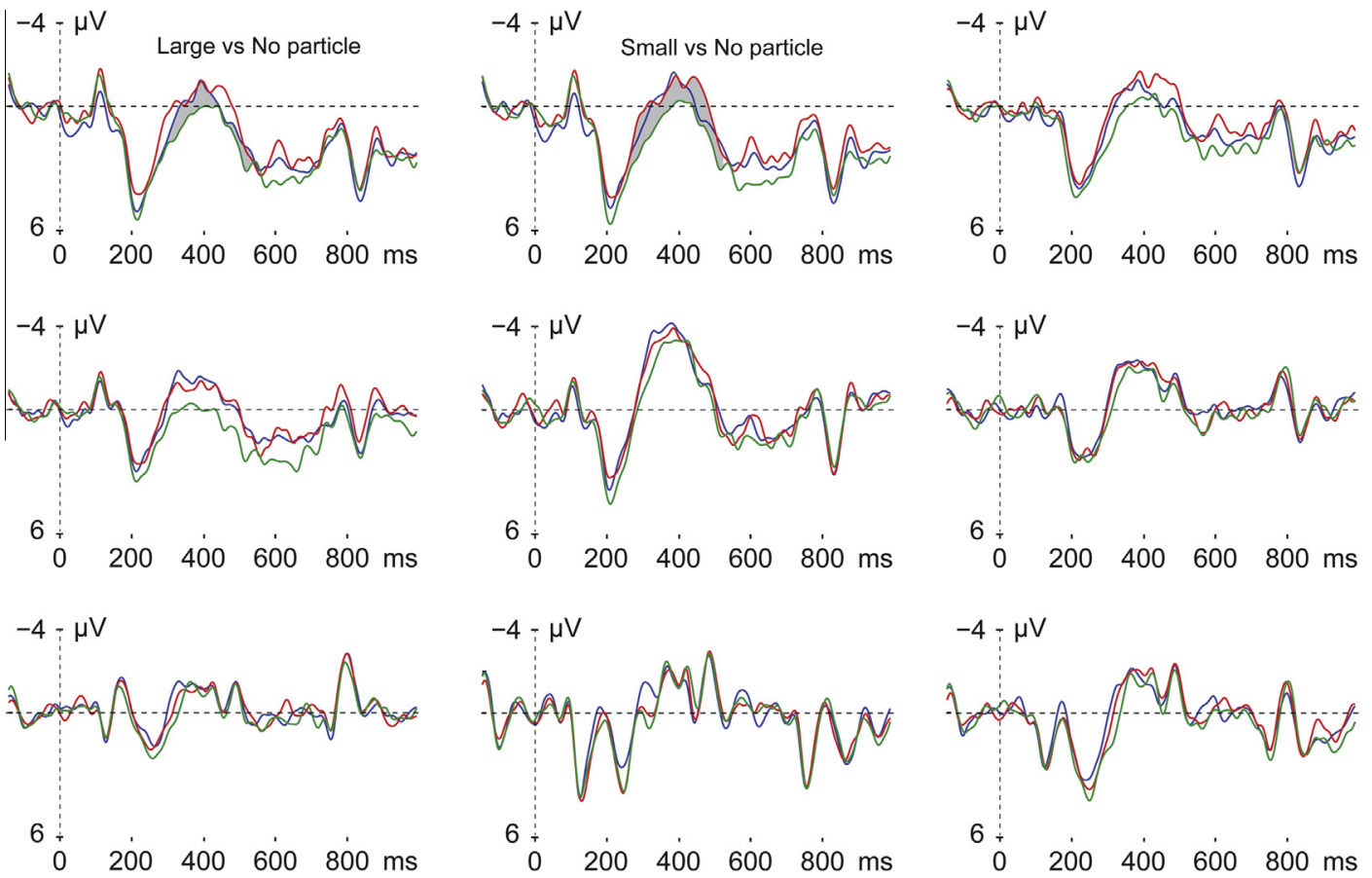

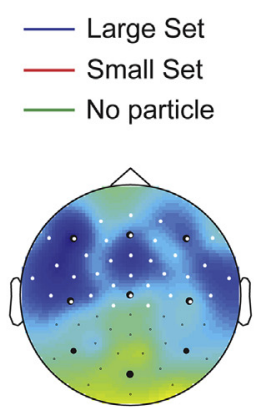

Large vs No particle

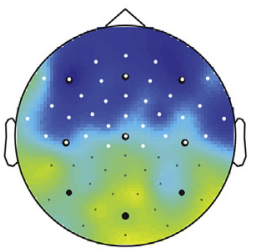

Small vs No particle

$-1.5 \mu \mathrm{V} \quad 1.5$

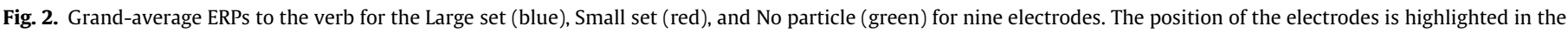

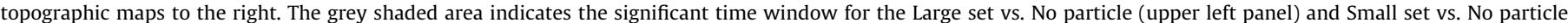

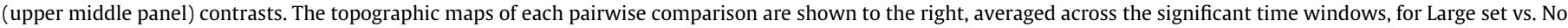
particle (upper) and Small set vs. No particle (lower). Channels belonging to the significant cluster are marked in white.
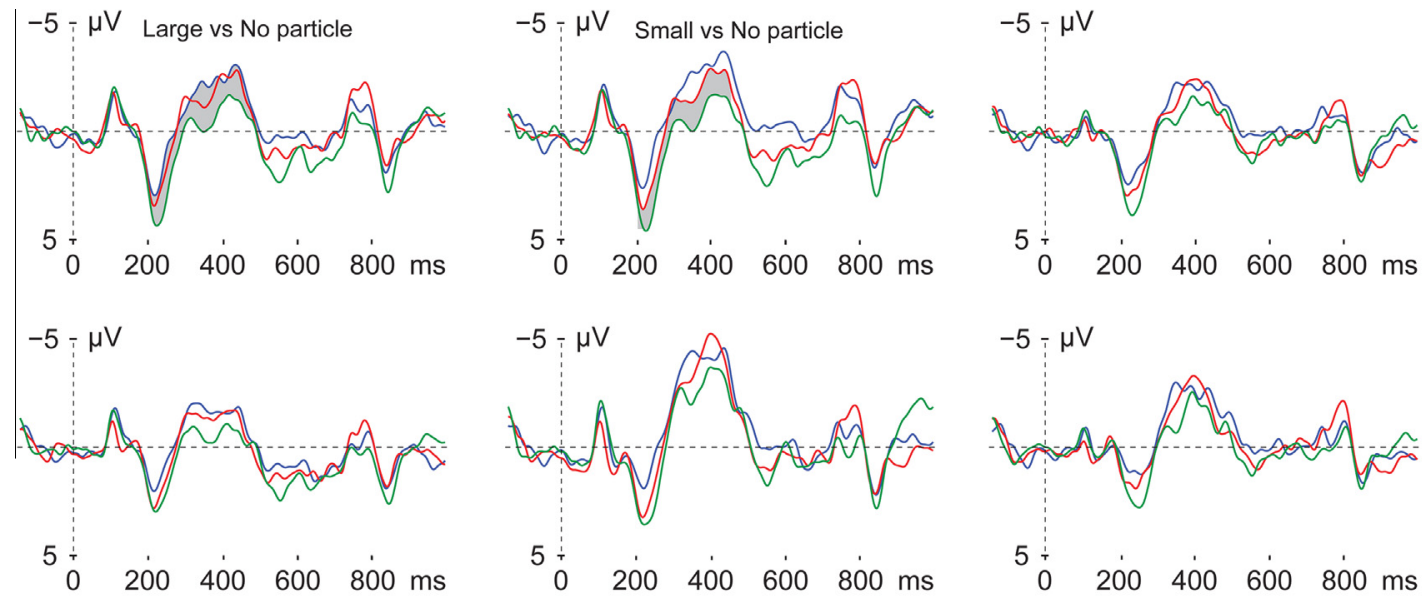

$-5-\mu \mathrm{V}$
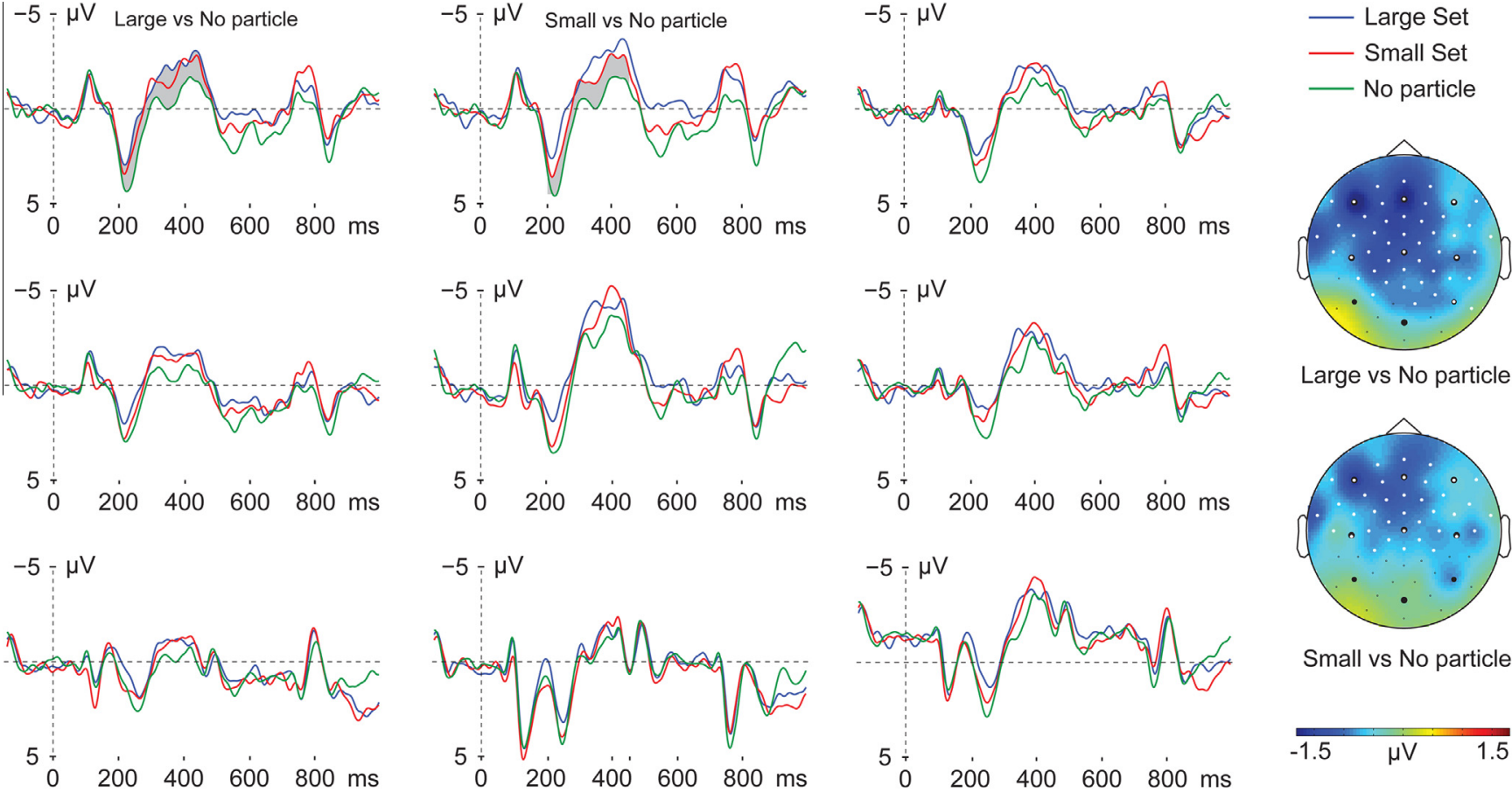

Large vs No particle

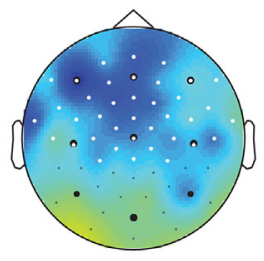

Small vs No particle

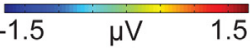

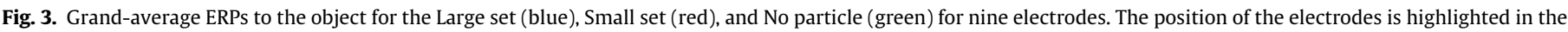

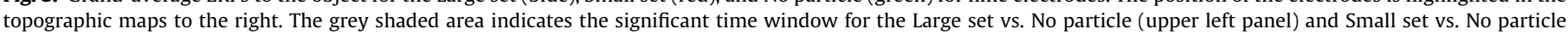

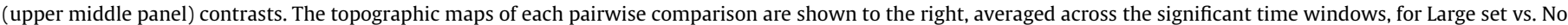
particle (upper) and Small set vs. No particle (lower). Channels belonging to the significant cluster are marked in white.

particle condition. These effects have a slightly left-lateralised scalp topography, as shown to the right of the figure. No significant clusters were detected for the comparison between the Large and the Small sets at the verb.

\subsubsection{Object}

Fig. 3 shows the ERPs to the object for nine representative channels. The position of these nine channels is highlighted in the topographies on the right. An increased negativity was detected 
for the Large set relative to the No particle condition, $p=.007$, and for the Small set relative to the No particle condition, $p=.044$. This increased negativity was detected between 184 and $476 \mathrm{~ms}$ for the Large set relative to the No particle condition, and between 198 and $454 \mathrm{~ms}$ for the Small set relative to the No particle condition. These effects have a slightly left-lateralised scalp topography, as shown to the right of the figure. No significant clusters were detected for the comparison between the Large and Small sets at the object.

In an additional analysis, both for the ERPs to the verb and for the ERPs to the object, we wanted to verify whether the observed anterior-negativity effects might be attributable to experimentspecific strategic processing, because of the relatively high frequency of occurrence of particle verbs in our stimulus materials. If this were the case, we would expect these effects to develop during the course of the experiment. We therefore split the data into two parts, the first part including only the sentences from the first half of the experiment, whereas the second part included the sentences from the second half of the experiment. In both halves the same anterior negativity effects were observed, indicating that these effects do not emerge in the course of the experiment as a result of experiment-specific strategic processing (see Supplement).

\subsection{Lexical access and long-term memory}

For the lexical-access question, the ERPs at the particle were compared across the three conditions (e.g., verb bellen 'to call': Wij bellen de afspraak van vanmiddag af (well-formed) / terug (semantic violation) / toe (morpholexical violation), 'We call the appointment of this afternoon off/back/to'.
Fig. 4 shows the ERPs to the particle for nine representative channels. The position of these nine channels is highlighted in the topographies to the right. The three conditions gradually differed from each other, with the Morpholexical violation condition eliciting the largest negativity, followed by the Semantic violation condition, relative to the Well-formed. More specifically, the ERPs to the Semantic violation condition were more negative than the ERPs to the Well-formed condition, $p=.036$. This cluster was detected between 260 and $420 \mathrm{~ms}$. The ERPs to the Morpholexical violation condition were also more negative than to Well-formed, $p=.001$. This cluster was detected between 254 and $480 \mathrm{~ms}$. Finally, the ERPs to the Morpholexical violation condition were more negative than to the Semantic violation condition, $p=.032$. This cluster was detected between $270 \mathrm{~ms}$ and $508 \mathrm{~ms}$. The scalp distribution of these negativities is mainly centro-parietal, as shown on the right of the figure. These results suggest a graded N400 effect, with the largest amplitude in the Morpholexical violation condition, followed by the Semantic violation condition, relative to the Well-formed condition.

\section{Discussion}

We first summarise and briefly address the findings related to each research question separately and then provide a general discussion.

\subsection{Syntactic dependencies and working memory}

For our first question (whether the possibility of a dependency is detected at the head verb or only at the particle), three sets of sentences were constructed based on the number of particles that
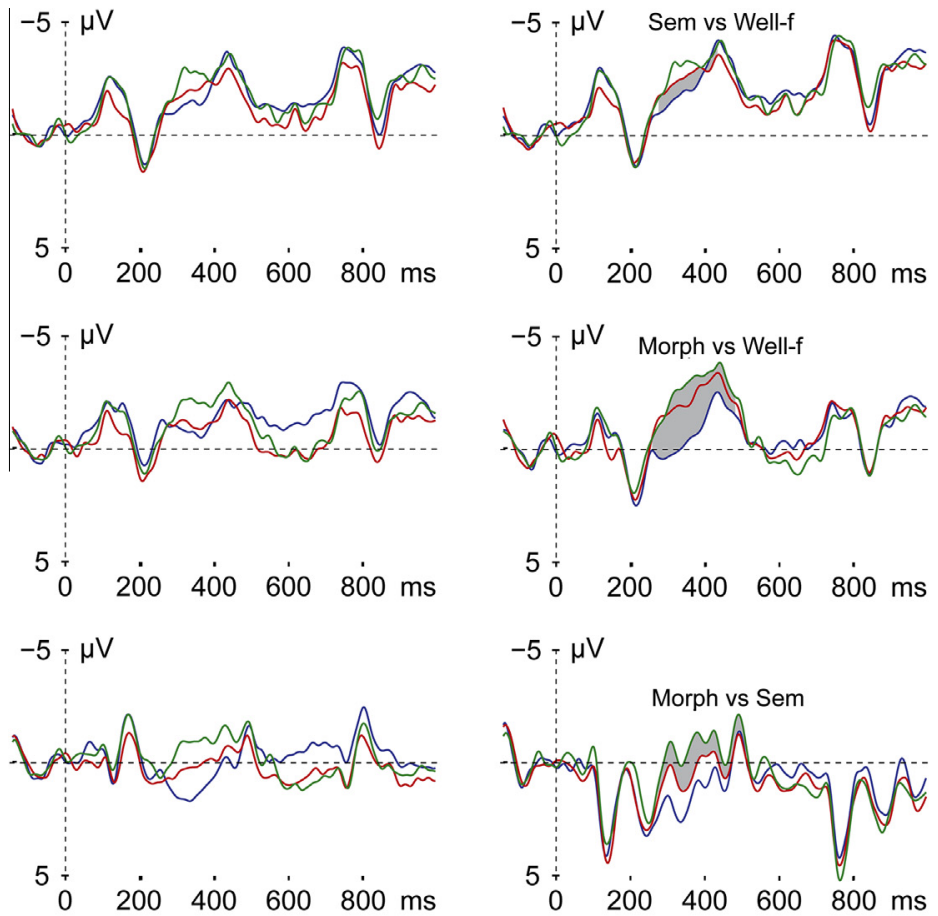
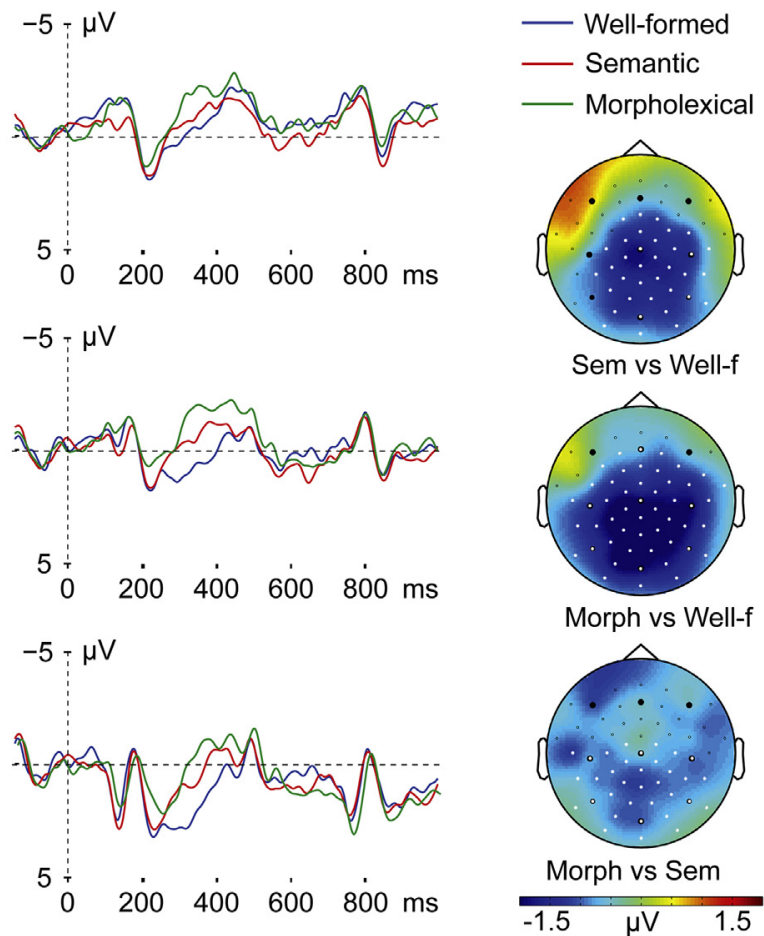

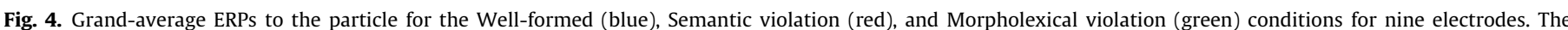

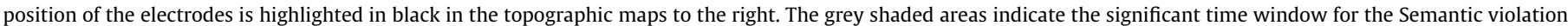

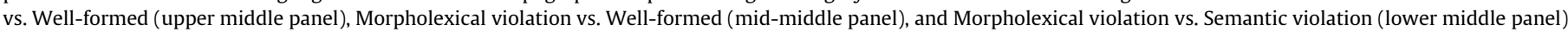

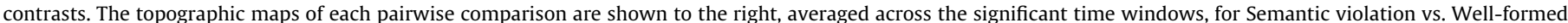

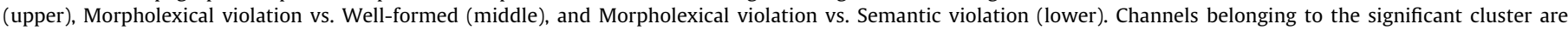
marked in white. Well-f = Well-formed; Sem, Semantic = Semantic violation; Morph, Morphlexical = Morpholexical violation. 
the lexicon entry of a single verb would allow for (Large set, Small set, and No particle condition). Spanning the upstream verb and object, we observed an anterior, slightly left-lateralised negativity for the Large set relative to the No particle condition and for the Small set relative to the No particle condition. The ERPs to the Small and Large set were not found to differ.

Taken together, these results indicate that sentence processing is sensitive to the general possibility of a downstream particle, but appears insensitive to the number of possible downstream particles as specified by the verb's lexical entry. Regarding the functional interpretation of the observed negativity, we suggest it be a member of the family of (sustained) left anterior negativities (LANs), reported previously in studies on sentence processing, generally interpreted as an index of keeping items active in working memory for later integration (for review, see Kutas et al., 2006). Left anterior negativities starting as early as $300 \mathrm{~ms}$ have been found during the storage of words relative to non-words (Ruchkin \& et al., 1999), ambiguous words relative to unambiguous words (Hagoort \& Brown, 1994), wh-dependencies (Clahsen \& Featherston, 1999; Felser et al., 2003; Fiebach, Schlesewsky, \& Friederici, 2001; Fiebach et al., 2002; Kluender \& Kutas, 1993; Phillips et al., 2005; Ueno \& Kluender, 2003), and object- as compared to subject-relative clauses (King \& Kutas, 1995).

Thus, the present LAN effect can be interpreted in different ways: First, it may reflect the increased working-memory load associated with storage of the upstream verb (Kluender \& Kutas, 1993). Second, it may index the activation of multiple readings of the verb (Hagoort \& Brown, 1994), or third, it may index the increased effort of holding a semantically underspecified lexical item in working memory (King \& Kutas, 1995). There are, however, problems with the latter two interpretations. If multiple readings or semantic underspecification would have led to the increased negativity we observed, then the Large set should also have differed from the Small set, because the verbs in the Large set have more possible readings than the verbs in the Small set, and the Large-set verbs are also more semantically underspecified than the Small-set verbs. However, no differences between the Large and Small set were observed in the amplitude of the anterior negativity. Furthermore, previously observed underspecificationrelated negativities were of a slightly longer latency and different scalp distribution than the negativity observed in the present study (King \& Kutas, 1995). Finally, if our LAN is reflecting verb ambiguity, it should be confined to the verb epoch, because we know from the pre-tests that the object dramatically increases the predictability of the particle (cloze probabilities around $82 \%$ ), that is, the ambiguity is greatly decreased at the object. Since we also observed the LAN effect at the object, it is more likely that the present LAN effect reflects working-memory storage of the verb until its particle is encountered to close the dependency.

It could be argued that the number of possible particles a verb allows for is correlated with the number of idiomatic particle-verb combinations. It should be noted, however, that idiomaticity seems to affect the N400 component, but does not elicit LANs (Rommers, Dijkstra, \& Bastiaansen, 2013; see also Vespignani, Canal, Molinaro, Fonda, \& Cacciari, 2010). So our LAN results seem to be independent of idiomaticity. Moreover, since each verb-particle combination constitutes an independent lexical item, there is no a-priori reason to assume, or expect, that verbs with small or large sets of particles systematically differ in terms of idiomaticity. Therefore, the relation between the number of possible particles and particle-verb idiomaticity is unlikely to account for our LAN effects.

From a processing point of view, the fact that the present LAN is larger only for the particle completion sentences relative to the sentences without a possible particle completion indicates that, when encountering a verb whose lexical entry allows for a particle, a downstream particle and an according verb-particle dependency are postulated (Gibson, 1998). Furthermore, the finding indicates that the number of possible particles a verb's lexical entry allows for does not affect this postulation-that is, it may be a syntactic rather than a semantic phenomenon.

\subsection{Lexical access and long-term memory}

To address the question of lexical access in particle-verb processing, our second manipulation used sentences that contained existing particle verbs forming coherent sentences (Well-formed), existing particle verbs forming semantic anomalies in sentence context (Semantic violation), or non-existing particle verbs, created by combining an existing verb with a mismatching existing particle, also forming a semantic anomaly in the sentence context (Morpholexical violation). A graded N400 effect was observed at the particle for the two violation conditions relative to the Wellformed, with the Morpholexical violation condition, crucially, eliciting a larger effect than the Semantic violation condition relative to the Well-formed.

The increased N400 for the Semantic violation relative to the Well-formed condition can be readily explained by the mismatch between the particle and the preceding sentence context (Kutas \& Hillyard, 1980; for reviews, see Kutas \& Federmeier, 2011; Kutas et al., 2006; Lau et al., 2008). Similarly, the increased N400 for the Morpholexical relative to the Semantic violation condition could be explained by such a mismatch. However, we argue that an alternative explanation is more likely. In both the Semantic and the Morpholexical violation conditions there is a full mismatch between the expected and the encountered particle but only the Morpholexical violation condition involves non-existing particle verbs, i.e., verbs that lack a lexical entry. Thus, the increased N400 for the Morpholexical relative to the Semantic violation condition in our view indicates that the particle triggered an (unsuccessful) attempt to access a lexical entry shared between the head verb and the particle.

An EEG study by Isel et al. (2005) provides converging evidence for this latter account. Their paradigm involved sentences with non-existing particle verbs (formed by adding particles to existing non-particle verbs), which were presented with prosody that either suggested a downstream particle (Morpholexical violation condition) or not. In the Well-formed condition, a legal particle verb was used with the correct prosody. An increased N400 was found at the particle only for the Morpholexical violation relative to the Well-formed condition, which, according to the authors, reflects the costs of the lexical search for the non-existing particle verb. In this case, the lexical search is more costly since there is no entry for that particle verb in long-term memory. These results are consistent with our proposal that the failure of lexical access for a particle verb is associated with an N400 effect.

As we noted earlier, there is no one-to-one relationship between N400 effects and lexical access (cf. Choudhary et al., 2009; Haupt et al., 2008; Janssen et al., 2006), so our conclusions are based on a plausibility argument. Future studies should address whether N400 effects in particle-verb processing during sentence comprehension are exclusively related to lexical access.

\section{General discussion}

In sum, we observed a LAN effect following a verb that allows for a potential downstream particle at the verb and at the object of the sentence. In addition, we observed that the occurrence of a downstream non-lexical verb particle increases the N400 amplitude at the particle over and above the N400 observed during a sentence-level semantic incongruity. These results suggest that the language system is sensitive to a possible downstream particle 
completion following verb encounter, and that on particle encounter, the particle verb's mental-lexicon entry is accessed (a second time).

A striking aspect of these results is the apparent early sensitivity of the system to the potential appearance of a downstream particle. This sensitivity may enable the system to plan the build-up of a proper syntactic structure ahead, that is, reserving certain syntactic slots downstream (Kamide, Scheepers, \& Altmann, 2003; Vosse \& Kempen, 2000) to constantly check the suitability of items stored in working memory as potential candidates for these slots (Clifton \& Frazier, 1988; Hawkins, 1999; Hawkins, 2004). While some authors have proposed that dependency formation may facilitate downstream processing due to increased predictability of upcoming material (Jaeger, Fedorenko, \& Gibson, 2005; Konieczny \& Döring, 2003; Levy, 2008; Vasishth, 2003), others stressed that it may hinder downstream processing due to increased workingmemory load (Frazier, 1987; Gibson, 1998; Grodner \& Gibson, 2005). Recently, Levy and Keller (2013) proposed to combine these perspectives, showing that predictability and storage demand are both important and independent features of incremental sentence processing. This proposal can explain why we observed both an early marker of working-memory pre-allocation (i.e., the LAN) and a late marker of reduced predictability (i.e., the N400) in the present study.

The proposal that words or phrases during sentence processing undergo both working-memory processes (i.e., storage) and longterm memory processes (i.e., predictability) may mirror Anders Ericsson and Kintsch's (1995) conceptualisation of working memory as the attentional focusing of long-term-memory content: If predictability is taken to reflect long-term-memory association and working-memory storage is taken as the selective-attentional activation of long-term-memory representations, the reduced $\mathrm{N} 400$ in the present data ultimately follows from the prior sustained attentional focusing of the particle verb's long-termmemory representation, as indexed by the negativity. This goes well with Lewis, Vasishth, and Van Dyke (2006) adaptation of Anders Ericsson and Kintsch's (1995) idea to the sentence-processing domain, according to which the raised activation level of words or phrases stored in working memory facilitates these words' or items' secondary access.

The pre-allocation of a proper syntactic structure may also not be the only reason for the system's early sensitivity to potential particle completions. As noted by some authors (Blom, 2005; Booij, 1990; Schreuder, 1990), many particle verbs have an opaque meaning, that is, the meaning of the particle verb cannot be derived compositionally from the meanings of the verb and the particle. Suppose that at the time the head verb is encountered, its meaning is retrieved and stored for further processing. In the case of an opaque particle verb, having only the meaning of the verb will not suffice since the meaning of the opaque particle verb is not compositional. However, if there is a lexical entry for the particle verb, the system can use the stored head verb to combine it with the particle and access the lexicon for the meaning of the opaque particle verb. The LAN effect in our data may reflect an underlying mechanism that keeps the head verb available in working memory for combination with a potential downstream particle, as indexed by the present N400 effect. The additional workingmemory load associated with keeping the head verb active may result in reduced lexical-access demands if the hypothesis of a particle completion proves true: The particle will then both have a place in the syntactic structure, and the long-term-memory retrieval of the particle verb's single lexical entry is facilitated. The processing of particle verbs thus seems to rely on a tight interaction between syntax and the lexicon. Our findings suggest that, provided the upstream detection of a syntactic dependency, the lexicon is accessed once a particle is encountered, in search for the lexical entry of a particle verb. If lexical information alone were used for particle-verb retrieval, any encountered preposition or adverb in the sentence would trigger particle-verb retrieval.

The proposed interplay between working memory and longterm memory during particle-verb processing is compatible with previously proposed neural architectures of language processing (Friederici, 2011; Hagoort, 2005). On a general level, such architectures converge in involving a working-memory buffer which transiently activates long-term-memory representations for the application of combinatorial processes (Baggio \& Hagoort, 2011). On the one hand, the present LAN's anterior and left-lateralised topography can point to generators in left prefrontal brain regions that have been proposed to activate for increasing syntacticworking-memory demands (Fiebach, Schlesewsky, Lohmann, von Cramon, \& Friederici, 2005; Makuuchi, Bahlmann, Anwander, \& Friederici, 2009; Santi \& Grodzinsky, 2007; Stromswold, Caplan, Alpert, \& Rauch, 1996): Particle-verb processing requires a syntactic link between the particle and its verb, but no compositional semantics. Furthermore, similar to our LAN, sustained negativities for increased syntactic-working-memory demands exhibit a left anterior scalp topography (Clahsen \& Featherston, 1999; Felser et al., 2003; Fiebach et al., 2001; Kluender \& Kutas, 1993; Phillips et al., 2005; Ueno \& Kluender, 2003), unlike temporo-parietally generated sustained effects during retention tasks that focus less on syntactic structure (Meyer, Obleser, Anwander, \& Friederici, 2012; Meyer, Obleser, \& Friederici, 2013). Our interpretation of the present $\mathrm{N} 400$, on the other hand, is not only in line with classical proposals (Binder, Desai, Graves, \& Conant, 2009; Van Petten, 1993; for review, see Van Petten \& Luka, 2012), but its topography is compatible with mental-lexicon-relevant generators in bilateral temporal cortices (Johnson \& Hamm, 2000; Maess, Herrmann, Hahne, Nakamura, \& Friederici, 2006; Silva-Pereyra et al., 2003; Simos, Basile, \& Papanicolaou, 1997). Nevertheless, caution remains at order in interpreting the present scalp-level ERP data in terms of their cortical sources.

\section{Conclusion}

Our results suggest that during sentence processing, upstream verbs trigger the early postulation of a downstream particle, and accompanying working-memory storage of the head verb. In case of an actual downstream particle, the stored head verb is used in the integration with its particle, facilitating the retrieval of the particle verb's single mental-lexicon entry from long-term memory. The study of particle verbs in sentence context may open a window into the interaction of syntactic and lexical aspects of sentence processing. As such, insights into the processing of discontinuous lexical dependencies may provide valuable information for theories of sentence comprehension.

\section{Acknowledgments}

The authors thank Joost Rommers, Karl-Magnus Petersson, and Nan van de Meerendonk for helpful feedback.

\section{Appendix A. Supplementary material}

Supplementary data associated with this article can be found, in the online version, at http://dx.doi.org/10.1016/j.bandl.2013.09. 015 .

\section{References}

Anders Ericsson, K., \& Kintsch, W. (1995). Long-term working memory. Psychological Review, 102, 211-245. 
Baayen, H., Piepenbrock, R., \& van Rijn, H. (1995). The CELEX Lexical Database, Release 2 (CD-ROM). University of Pennsylvania, PA: Linguistic Data Consortium.

Baggio, G., \& Hagoort, P. (2011). The balance between memory and unification in semantics: A dynamic account of the N400. Language and Cognitive Processes, 26, $1338-1367$.

Binder, J., Desai, R., Graves, W., \& Conant, L. (2009). Where is the semantic system? A critical review and meta-analysis of 120 functional neuroimaging studies Cerebral Cortex, 19, 2767-2796.

Blom, C. (2005).Complex predicates in Dutch: Synchrony and diachrony. $\mathrm{PhD}$ dissertation, Vrije Universiteit Amsterdam (LOT Publications Series 111).

Bloom, P. A., \& Fischler, I. (1980). Completion norms for 329 sentence contexts. Memory E' Cognition, 8, 631-642.

Booij, G. (1990). The boundary between morphology and syntax: Separable complex verbs in Dutch. In G. Booij \& J. van Marle (Eds.), Yearbook of morphology 1990 (pp. 45-63). Dordrecht: Foris.

Booij, G. (2002). Separable complex verbs in Dutch: A case of periphrastic word formation. In N. Dehé (Ed.), Verb particle explorations (pp. 21-41). Berlin: De Gruyter.

Cappelle, B., Shtyrov, Y., \& Pulvermüller, F. (2010). Heating up or cooling up the brain? MEG evidence that phrasal verbs are lexical units. Brain and Language, $115,189-201$.

Choudhary, K. K., Schlesewsky, M., Roehm, D., \& Bornkessel-Schlesewsky, I. (2009). The N400 as a correlate of interpretively relevant linguistic rules: Evidence from Hindi. Neuropsychologia, 47, 3012-3022.

Clahsen, H., \& Featherston, S. (1999). Antecedent priming at trace positions: Evidence from German scrambling. Journal of Psycholinguistic Research, 28, 415-437.

Clifton, C., \& Frazier, L. (1988). Comprehending sentences with long-distance dependencies. In G. Carlson \& M. K. Tanenhaus (Eds.), Linguistic structure in language processing (pp. 273-317). Dordrecht: Reidel Press.

Felser, C., Clahsen, H., \& Münte, T. F. (2003). Storage and integration in the processing of filler-gap dependencies: An ERP study of topicalization and whmovement in German. Brain and Language, 87, 345-354.

Fiebach, C. J., Schlesewsky, M., \& Friederici, A. D. (2001). Syntactic working memory and the establishment of filler-gap dependencies: Insights from ERPs and fMRI Journal of Psycholinguistic Research, 30, 321-338.

Fiebach, C. J., Schlesewsky, M., \& Friederici, A. D. (2002). Separating syntactic memory costs and syntactic integration costs during parsing: The processing of German WH-questions. Journal of Memory and Language, 47, 250-272.

Fiebach, C. J., Schlesewsky, M., Lohmann, G., von Cramon, D., \& Friederici, A. (2005). Revisiting the role of Broca's area in sentence processing: Syntactic integration versus syntactic working memory. Human Brain Mapping, 24, 79-91.

Frazier, L. (1987). Sentence processing: A tutorial review. In M. Coltheart (Ed.), Attention and performance 12: The psychology of reading (pp. 559-586). Hove: Erlbaum.

Frazier, L., Flores d'Arcais, G. B., \& Coolen, R. (1993). Processing discontinuous words: On the interface between lexical and syntactic processing. Cognition, 47, 219-249.

Friederici, A. (2011). The brain basis of language processing: From structure to function. Physiological Reviews, 91, 1357-1392.

Gibson, E. (1998). Linguistic complexity: Locality of syntactic dependencies. Cognition, 68, 1-76.

Grodner, D., \& Gibson, E. (2005). Consequences of the serial nature of linguistic input for sentenial complexity. Cognitive Science: A Multidisciplinary Journal, 29, $261-290$.

Groppe, D. M., Urbach, T. P., \& Kutas, M. (2011). Mass univariate analysis of eventrelated brain potentials/fields I: A critical tutorial review. Psychophysiology, 48 1711-1725.

Hagoort, P., \& Brown, C. (1994). Brain responses to lexical ambiguity resolution and parsing. In C. Clifton, Jr., L. Frazier, \& K. Rayner (Eds.), Perspectives on sentence processing (pp. 45-81). Hillsdale, NJ: Erlbaum.

Hagoort, P. (2005). On Broca, brain, and binding: A new framework. Trends in Cognitive Sciences, 9, 416-423.

Hauk, O., Davis, M. H., Ford, M., Pulvermüller, F., \& Marslen-Wilson, W. D. (2006). The time course of visual word recognition as revealed by linear regression analysis of ERP data. Neurolmage, 30, 1383-1400.

Haupt, F. S., Schlesewsky, M., Roehm, D., Friederici, A. D., \& Bornkessel-Schlesewsky, I. (2008). The status of subject-object reanalyses in the language comprehension architecture. Journal of Memory and Language, 59, 54-96.

Hawkins, J. (1999). Processing complexity and filler-gap dependencies across grammars. Language, 75, 244-285.

Hawkins, J. (2004). Efficiency and complexity in grammars. Oxford: Oxford University Press.

Hillert, D., \& Ackerman, F. (2002). Accessing and parsing phrasal predicates. In N Dehé, R. Jackendoff, A. McIntyre, \& S. Urban (Eds.), Verb-particle explorations (pp. 21-41). Berlin/New York: Mouton de Gruyter.

Hoekstra, T. (1988). Small clause results. Lingua, 74, 101-139.

Hoekstra, T. Lansu, M., \& Westerduin, M. (1987). Complexe verba. Glot, 10, 61-79.

Isel, F., Alter, K., \& Friederici, A. D. (2005). Influence of prosodic information on the processing of split particles: ERP evidence from spoken German. Journal of Cognitive Neuroscience, 17, 154-167.

Jackendoff, R. (2002). English particle constructions, the lexicon, and the autonomy of syntax. In N. Dehé, R. Jackendoff, A. McIntyre, \& S. Urban (Eds.), Verb-particle explorations (pp. 67-94). Berlin: Mouton de Gruyter.
Jaeger, F., Fedorenko, E., \& Gibson, E. (2005). Dissociation between production and comprehension complexity. In 18th CUNY Sentence processing conference, New York, NY.

Janssen, U., Wiese, R., \& Schlesewsky, M. (2006). Electrophysiological responses to violations of morphosyntactic and prosodic features in derived German nouns. Journal of Neurolinguistics, 19, 466-482.

Johnson, B., \& Hamm, J. (2000). High-density mapping in an N400 paradigm: Evidence for bilateral temporal lobe generators. Clinical Neurophysiology, 111, 532-545.

Kamide, Y., Scheepers, C., \& Altmann, G. T. M. (2003). Integration of syntactic and semantic information in predictive processing: Cross-linguistic evidence from German and English. Journal of Psycholinguistic Research, 32, 37-55.

King, J. W., \& Kutas, M. (1995). Who did what and when? Using word- and causallevel ERPs to monitor working memory usage in reading. Journal of Cognitive Neuroscience, 7, 376-395.

Kluender, R., \& Kutas, M. (1993). Bridging the gap: Evidence from ERPs on the processing of unbounded dependencies. Journal of Cognitive Neuroscience, 5, $196-214$.

Konieczny, L. \& Döring, P. (2003). Anticipation of clause-final heads: Evidence from eye-tracking and SRNs. In Proceedings of ICCS/ASCS, 2003.

Konopka, A. E., \& Bock, K. (2008). Lexical or syntactic control of sentence formulation? Structural generalizations from idiom production. Cognitive Psychology, 58, 68-101.

Kutas, M. (1993). In the company of other words: Electrophysiological evidence for single-word and sentence context effects. Language and Cognitive Processes, 8 , 533-572.

Kutas, M., \& Federmeier, K. (2011). Thirty years and counting: Finding meaning in the N400 component of the event-related brain potential (ERP). Annual Review of Psychology, 62, 621-647.

Kutas, M., \& Hillyard, S. (1980). Reading senseless sentences: Brain potentials reflect semantic incongruity. Science, 207, 203-205.

Kutas, M., van Petten, C., \& Kluender, R. (2006). Psycholinguistics electrified II: 1994-2005. In M. Traxler \& M. A. Gernsbacher (Eds.), Handbook of psycholinguistics (2nd ed., pp. 659-724). New York: Elsevier.

Lau, E. F., Phillips, C., \& Poeppel, D. (2008). A cortical network for semantics: (De)constructing the N400. Nature Reviews Neuroscience, 9, 920-933.

Levy, R. (2008). Expectation-based syntactic comprehension. Cognition, 106, 1126-1177

Levy, R. P., \& Keller, F. (2013). Expectation and locality effects in German verb-final structures. Journal of Memory and Language, 68, 199-222.

Lewis, R. L., Vasishth, S., \& Van Dyke, J. A. (2006). Computational principles of working memory in sentence comphrension. Trends in Cognitive Science, 10, 447-454.

Maess, B., Herrmann, C. S., Hahne, A., Nakamura, A., \& Friederici, A. D. (2006). Localizing the distributed language network responsible for the N400 measured by MEG during auditory sentence processing. Brain Research, 1096, 163-172.

Magnuson, J. S., Dixon, J. A., Tanenhaus, M. K., \& Aslin, R. N. (2007). The dynamics of lexical competition during spoken word recognition. Cognitive Science, 31, $133-156$.

Makuuchi, M., Bahlmann, J., Anwander, A., \& Friederici, A. (2009). Segregating the core computational faculty of human language from working memory. Proceedings of the National Academy of Sciences of the United States of America, 106, 8362-8367.

Maris, E., \& Oostenveld, R. (2007). Nonparametric statistical testing of EEG- and MEG-data. Journal of Neuroscience Methods, 164, 177-190.

McIntyre, A. (2007). Particle verbs and argument structure. Language and Linguistics Compass, 1, 350-397.

Meyer, L., Obleser, J., Anwander, A., \& Friederici, A. D. (2012). Linking ordering in Broca's area to storage in left temporo-parietal regions: The case of sentence processing. Neurolmage, 62, 1987-1998.

Meyer, L., Obleser, J., \& Friederici, A. D. (2013). Left parietal alpha enhancement during working memory-intensive sentence processing. Cortex, 49, 711-721.

Phillips, C., Kazanina, N., \& Abada, S. H. (2005). ERP effects of the processing of syntactic long-distance dependencies. Cognitive Brain Research, 22, 407-428.

Pulvermüller, F. et al. (2001). Memory traces for words as revealed by the mismatch negativity. NeuroImage, 14, 607-616.

Revill, K. P., Aslin, R. N., Tanenhaus, M. K., \& Bavelier, D. (2008). Neural correlates of partial lexical activation. Proceedings of the National Academy of Sciences of the USA, 105, 13111-13115.

Rommers, J., Dijkstra, T., \& Bastiaansen, M. C. M. (2013). Context-dependent semantic processing in the human brain: Evidence from idiom comprehension. Journal of Cognitive Neuroscience, 25, 762-776.

Ruchkin, D. et al. (1999). Lexical contributions to retention of verbal information in working memory: Event-related brain potential evidence. Journal of Memory and Language, 41, 345-364.

Santi, A., \& Grodzinsky, Y. (2007). Working memory and syntax interact in Broca's area. Neurolmage, $37,8-17$.

Schreuder, R. (1990). Lexical processing of verbs with separable particles. In G. Booij \& J. van Marle (Eds.), Yearbook of morphology (pp. 65-79). Dordrecht: Foris.

Silva-Pereyra, J., Rivera-Gaxiola, M., Aubert, E., Bosch, J., Galán, L., \& Salazar, A. (2003). N400 during lexical decision tasks: A current source localization study. Clinical Neurophysiology, 114, 2469-2486.

Simos, P., Basile, L., \& Papanicolaou, A. (1997). Source localization of the N400 response in a sentence-reading paradigm using evoked magnetic fields and magnetic resonance imaging. Brain Research, 762, 29-39. 
Smolka, E., Komlósi, S., \& Rösler, F. (2009). When semantics means less than morphology: Processing German prefixed verbs. Language and Cognitive Processes, 24, 337-375.

Stromswold, K., Caplan, D., Alpert, N., \& Rauch, S. (1996). Localization of syntactic comprehension by positron emission tomography. Brain and Language, 52, $452-473$.

Taylor, W. L. (1953). Cloze procedure: A new tool for measuring readability. Journalism Quarterly, 30, 415-433.

Ueno, M., \& Garnsey, S. M. (2008). An ERP study of the processing of subject and object relative clauses in Japanese. Language and Cognitive Processes, 23, 646-688.

Ueno, M., \& Kluender, R. (2003). Event-related brain indices of Japanese scrambling. Brain and Language, 86, 243-271.

Ullman, M. T. (2001). A neurocognitive perspective on language: The declarative/ procedural model. Nature Reviews Neuroscience, 2, 717-726.

Van Petten, C. (1993). A comparison of lexical and sentence-level context effects in event-related potentials. Language and Cognitive Processes, 8, 485-531.
Van Petten, C., \& Luka, B. J. (2012). Prediction during language comprehension: Benefits, costs, and ERP components. International Journal of Psychophysiology, 83, $176-190$

Vasishth, S. (2003). Working memory in sentence comprehension: Processing Hindi center embeddings. New York, NY: Routledge.

Vespignani, F., Canal, P., Molinaro, N., Fonda, S., \& Cacciari, C. (2010). Predictive mechanisms in idiom comprehension. Journal of Cognitive Neuroscience, 22 $1682-1700$.

Vosse, T., \& Kempen, G. (2000). Syntactic structure assembly in human parsing: A computational model based on competitive inhibition and a lexicalist grammar. Cognition, 75, 105-143.

World Medical Association (1995). Declaration of Lisbon on the Rights of the Patient. Adopted by the 34th World Medical Assembly, Lisbon, Portugal September/October 1981 and amended by the 47th General Assembly, Bali, Indonesia, September 1995

Zwitserlood, P., Bolwiender, A., \& Drews, E. (2004). Priming morphologically complex verbs by sentence contexts: Effects of semantic transparency and ambiguity. Language and Cognitive Processes, 20, 395-415. 